Archives de sciences sociales des religions

176 | octobre-décembre 2016

Bulletin Bibliographique

\title{
Frédérique Neau-Dufour, Geneviève de Gaulle Anthonioz. L'autre de Gaulle
}

Paris, Éditions du Cerf, 2015, 368 p.

Jean-Dominique Durand

\section{OpenEdition}

\section{Journals}

Édition électronique

URL : http://journals.openedition.org/assr/28309

DOI : $10.4000 /$ assr.28309

ISSN : $1777-5825$

Éditeur

Éditions de l'EHESS

Édition imprimée

Date de publication : 31 décembre 2016

Pagination : 362

ISSN : 0335-5985

Référence électronique

Jean-Dominique Durand, «Frédérique Neau-Dufour, Geneviève de Gaulle Anthonioz. L'autre de Gaulle », Archives de sciences sociales des religions [En ligne], 176 | octobre-décembre 2016, mis en ligne le 20 juillet 2017, consulté le 24 septembre 2020. URL : http://journals.openedition.org/assr/28309 ; DOI : https://doi.org/10.4000/assr.28309

Ce document a été généré automatiquement le 24 septembre 2020.

(c) Archives de sciences sociales des religions 


\section{Frédérique Neau-Dufour, Geneviève de Gaulle Anthonioz. L'autre de Gaulle}

Paris, Éditions du Cerf, 2015, 368 p.

Jean-Dominique Durand

\section{RÉFÉRENCE}

Frédérique Neau-Dufour, Geneviève de Gaulle Anthonioz. L'autre de Gaulle, Paris, Éditions du Cerf, 2015, 368 p.

1 L'abbé Journet a dit de Geneviève de Gaulle (1920-2002) qu'elle était "une âme indomptable avec une ligne de conduite intangible». Ces mots résument sa vie: résistante dès le début de l'Occupation, à Rennes puis à Paris, cette nièce du général de Gaulle survécut au camp de Ravensbrück où elle fut déportée en février 1944. Elle avait œuvré notamment au sein du groupe du Musée de l'Homme, puis dans le réseau Défense de la France. Après la guerre elle présida l'Association nationale des anciennes déportées et internées de la Résistance (ADIR), puis elle s'engagea avec l'abbé Joseph Wresinski et ATD Quart-Monde, qu'elle présida de 1964 à 1998, dans une nouvelle résistance contre la pauvreté jusqu'à obtenir enfin en 1998 le vote par le Parlement d'une loi d'Orientation contre la grande pauvreté. Elle fut membre également du Conseil économique et social. En 2015, elle entre au Panthéon. C'est à cette occasion que Frédérique Neau-Dufour a réédité cette biographie déjà publiée en 2004. Agrégée d'Histoire, Docteur en Histoire avec une thèse sur Ernest Psichari (Éditions du Cerf, 2001, 269 p.), elle s'est affirmée comme historienne de la famille de Gaulle (elle a été un temps chargée de recherches à la Fondation Charles de Gaulle) : elle a publié en 2010 une véritable somme sur Yvonne de Gaulle (Fayard, 2010, 610 p.), et en 2013, La première Guerre de Charles de Gaulle 1914-1918 (Éditions Tallandier, 384 p.). Elle est actuellement 
directrice du Centre européen du résistant déporté sur le site du camp de NatzwillerStruthof.

2 L'ouvrage proposé est bien documenté, et de ce fait on regrette l'absence d'appareil scientifique, réduit à quelques notes renvoyées en fin de volume. Sans doute est-ce là une volonté de l'éditeur, afin de donner au livre un aspect "grand public ». C'est regrettable d'autant plus qu'il est fort bien écrit. L'indication des sources et d'une bibliographie n'exclut pas une diffusion large. Un index des noms de personnes est heureusement présent.

Geneviève de Gaulle Anthonioz était une catholique pratiquante, pour qui la foi a été un moteur de son action. Cet aspect est tellement important dans sa vie, qu'il aurait été utile de lui consacrer un chapitre en rassemblant les différents éléments épars tout au long du livre. De la religion de l'enfance transmise par ses parents, qui a résisté aux nombreuses épreuves familiales (décès prématuré de sa mère et de sa sœur, remariage du père), à la rencontre avec le père Wresinski, en passant par la prison et l'ignominie du camp de concentration, il y a un parcours spirituel qui mérite d'être analysé plus profondément. Quelle est sa prière, quel enseignement catholique donne-t-elle à ses enfants? Quelle a été l'influence de l'abbé Journet? Fondateur de la revue Nova et Vetera en 1926, ce dernier a exercé une grande influence sur toute une génération. Il réunissait avant la guerre un groupe de jeunes lycéens, au cours desquelles il mettait en garde contre le nazisme et l'antisémitisme. Parmi eux, avec d'autres, appelés à un grand destin au sein de l'Église comme le père Georges Cottier, Bernard Anthonioz qui épousa Geneviève de Gaulle en 1946. C'est l'abbé Journet qui célébra le mariage, et toute sa vie il accompagna la famille sur le plan spirituel. Chaque année Geneviève faisait une retraite avec lui. Or Journet était au cœur de tout un réseau, avec notamment Jacques et Raïssa Maritain, mais aussi Mgr Montini, qui devint pape Paul VI en 1963, et bien d'autres comme le maire de Florence Giorgio La Pira. C'est un autre ami de Journet qu'elle retrouve à Paris à l'Église de Saint-Jacques-du-Haut-Pas, l'abbé Daniel Pézeril, puis elle se lie avec son successeur le père Jean Kammerer qui avait connu la déportation à Dachau. Son engagement total auprès des pauvres se fit au nom du Christ. L'auteur raconte sa première visite au bidonville de Noisy-le-Grand: «cette expérience constitue pour elle une anamnèse, la remontée d'un souvenir qui prend une terrible actualité et qui reste présent par-delà les siècles : "Des pauvres, vous en aurez toujours" annonçait le Christ dans l'Évangile» (p. 225). Elle y retrouve les odeurs et les souffrances du camp de Ravensbrück. Le nouveau combat qu'elle entreprend alors est un « combat pour le principe de la vie, de la tendresse, de l'amour» (p. 239). En cette femme de combat, Frédérique Neau-Dufour voit aussi « une mystique, vibrante et sensible " qu'elle compare à Thérèse d'Avila : "Sa foi est une immense demeure intérieure " (p. 300). Comparaison qu'il serait nécessaire d'éclairer, tout comme son amitié, à laquelle il n'est fait qu'une allusion passagère, avec Marc Chagall, et plus tard avec le père dominicain Kim En Joong, grand peintre de la lumière biblique. Il y a donc un ensemble d'allusions ou de brefs développements tout au long du livre qui, si rassemblés et approfondis, permettrait de tracer un intéressant portrait spirituel d'une femme au parcours extraordinaire qui a toujours agi en chrétienne, selon l'expression de Maritain. 